\title{
LOS TRABAJOS DE LA CONSTRUCCION EN 1400: PRIMEROS ENFOQUES
}

Por

DENIS MENJOT

(Universidad de Nize) 
La construcción y el textil son las dos actividades no agrícolas más importantes en la economía tradicional (1). Las dos utilizan grandes cantidades de materias primas, necesitan la colaboración y la intervención sucesiva de numerosos trabajadores especializados para la fabrica. ción, a gran escala, de un producto; las únicas pues, que ya son industriales en la baja Edad Media.

La construcción en Castilla no ha atraído la atención que se merece. Pero las fuentes son escasas (2). Las abellas y ricas series» contables que se encuentran en otras regiones y los registros de deliberaciones apa-

(1) Por P. Chaunu: aLe bâtiment dans l'économie traditionnelle», en Le bátiment: enquête d'histoire économiqe $X I V^{\circ}-X I X^{\circ}$, Paris, 1971, t. I, pág. 19. aLe bâtiment est bien la première activité non agricolc dans l'économie traditionnelle en Europe,:

(2) A. Collantes de Terín SANchez: Sevilla en la baja media, la ciudad y sus hombres, Sevilla, 1977, empadrona los menestrales de la construcción, su distribu. ción por collaciones; dedica un muy interesante capítulo a la casa: materiales y sistemas de construcción, tipología, pero no puede hacer un estudio económico y social del subsector de la construcción. 
recen en ella rara vez antes del siglo $\mathrm{xv}$, y a veces tarde en el siglo y no en todas las ciudades; los registros notariales faltan (3).

Los archivos murcianos, aunque con lagunas, discontinuos y deficientes, ofrecen algunas posibilidades para un enfoque económico y social de los oficios de esta industria, a partir de finales del siglo XIv, en el marco preciso de esta ciudad frontera. Poseen, en efecto, una fuente inestimable e irreemplazable: los libros de cuentas. Aunque únicamente haya cinco para un período de 40 años; los de los ejercicios de 1391-1392, de 1395-1396, de 1407-1408, de 1426-1427 y de 1429-1430 (4). Nos imponen el marco cronológico. Cada uno de ellos se divide en dos partes. La segunda, con mucho la más importante, contiene los gastos de la ciudad registrados en orden cronológico y reagrupados a veces por puestos de trabajo, como en 1391-1392. En dichos gastos figuran por un lado los salarios de todos los trabajadores de la construcción que trabajan para la ciudad y cuyo clavario, que en los dos últimos libros tendrá el título de mayordomo, indica cada día los nombres; por otro lado, los precios de los materiales comprados para las obras y de su transporte hasta ella. La primera parte registra los ingresos que revelan el modo de financiamiento de los trabajos públicos. Estas cuentas están además frecuentemente llenas de comentarios, que permiten localizar la obra en la que se trabaja y precisar el estado en el que se encuentran los trabajos. La serie, casi completa, de los Libros de Ordenaciones, gracias a los estatutos y a los reglamentos que en ellas se encuentran, revela algunos elementos de la organización del trabajo, de las normas de fabricación, de las relaciones con las autoridades locales.

Este inventario de las fuentes incitaría más bien a renunciar a nuestra empresa. Son escasas, demasiado para poder mostrar una evolución.

(3) En otros países y ciudades, favorecidos por la documentación, la construcción ha dado lugar a notables trabajos. Entre otros, en Inglaterra, D. KNOOP y G. P. JoNEs: The medieval mason. Manchester, 1933. En Flandes: J. P. Sosson: Les travaux publics de la ville de Bruges, $X I V^{\circ}$ et $X V^{\circ}$, Bruxelles, 1977.

(4) A.M.M., Actas Capitulares, Libros de Cuentas (C. M. en adelante), 1391-92, 1395-96, 1407-08, 1426-27, 1429-30. 
Su alcance es limitado. La ausencia de contratos de empleo y de aprendizaje, de testamentos, de inventarios post-mortem, de padrones, no permite conocer las fortunas, las condiciones de vida, ni muchos aspectos de las condiciones de trabajo. Finalmente, esta documentación no aporta más que algunos esclarecimientos, y aún así éstos no van sin problemas ni incertidumbres, acerca del sector de la construcción y de los efectivos de asalariados que trabajan en él, acerca de la organización de su trabajo, de su poder adquisitivo y de su nivel de vida. Algunos esclarecimientos solamente, pero en este sector de la historia económica y social en el que, particularmente los últimos aspectos, permanecen aen la noche más oscura» (5), he estimado que podian ser útiles.

\section{I) EL SECTOR DE LA CONSTRUCCION Y SU EFECTIVO DE ASA- LARIADOS}

Cuáles son los efectivos de los trabajadores del sector de la construcción? Resolver esta cuestión consiste en determinar el valor de sus salarios como índice de los movimientos globales de la economía murciana puesto que, en la medida en que trabajando en obras en las que la colaboración de las diferentes profesiones y de una mano de obra considerable es obligatoria, podemos considerarlos como asalarios-tipo» (6). Su resolución es pues fundamental, y constituye un prealable indispensable (7).

Sin embargo, dar cifras muy precisas es perfectamente imposible a falta de un censo de estos trabajadores. No podemos conocer con exac-

(5) J. GAUTIER-DALCHE: Histoire économique et sociale de l'Espagne chrétienne au Moyen-Age, París, 1976, pág. 224.

(6) M. BLOCH: aLe maçon médiéval: problèmes de salariatı, en Annales d'his. toria economique et sociale, t. VII, 1935, citado por B. GEREMEK: aLes salariés et le salariat dans les villes au cours du bas Moyen-Ages, en Troisième conférence inter. nationale d' Histoire Economique, Munich, 1965, pág. 596.

(7) R. Rosuno: eSalaires et Histoire Economique», en ibid., pág. 492, insiste en un punto que: ale vrai probleme est de reconnaître non pas un mouvement de salaires mais le mouvement de la masse des salaires payés pour une population active donnée ...donc le marché de la main-d'oeuvres. 
titud más que la mano de obra que trabajaba en las obras públicas. Podemos, sin embargo, hacernos una idea de su número gracias al lugar que ocupa la industria de la construcción en la vida murciana. $Y$ ésta, por cierto, es bastante importante, sobre todo a partir de finales del siglo XIV.

Como todas las municipalidades de Europa Occidental, Murcia se preocupaba de la mejora, o cuando menos de la conservación en buen estado, de sus infraestructuras, y en primer lugar, y sobre todo, de sus fortificaciones (8), pues en la marca fronteriza de la que era la capital, la inseguridad era endémica. Un obrero de los adarves, escogido por el Concejo, se encargaba especialmente de ello. No transcurre ningún año sin que no haya una brecha que cerrar, un agujero que tapar, una alme. na que reconstruir, un muro que consolidar, una cerradura o una bisagra que cambiar, una torre que afianzar, montantes de las puertas que reemplazar, goznes que reforzar... A estos efectos, a fin de tranquilizar a la ciudad, y consciente de la importancia que representaba para la seguridad de la región y la suya propia el tener murallas en buen estado, el soberano les destinaba 10.000 maravedis del producto de las alcabalas. Las murallas, a pesar de todo, estaban en mal estado, las puertas principalmente, y cuando el peligro se hacia apremiante, las autoridades debían efectuar importantes trabajos, por ejemplo, en 1405, 1407 y 1408, 1429 y 1430 (9). Por último, no debemos olvidar entre estas construccio-

(8) Ph. Contamine: aLes fortifications urbaines en France à la fin du Moyen Age: aspects financiers et économiques", en Revue Historique, 1978.

(9) En 1391-92, labores de madera: 2 pares de puertas mayores, 6 pares de tapieras nuevas para las labores de los adarves, puertas nuevas para la casa de la prisión, las cameras de la Corte, la escalera del adarve. El 13 de enero 1405, Remir Sánchez, jurado clavario compró para los adarves: 500 cahíces de cal, 20.000 adrillos, 500 cahíces de arena, 500 cargas de cacales, y 100 maderas para cubrir las torres. En 1407 y 1408 , el Concejo somete a los habitantes a un impuesto de 6, 4 y 2 maravedís para la labor de los adarves, D. MenJor: aLe poids de la guerre dans l'économie murcienne, l'exemple de la campagne de $1407-08$, contre Grenades, en Miscelánea Medieval Murciana, t. II, págs. 47 y 52-53. A. C. Libro de Ordenaciones (L. O. en adelante), 9 de mayo 1413, dos omnes buenos (puestos por el Concejo) en uno con otros maestros albañiles declaran que necesita 560.090 maravedís para reparar e adobar los muros, torres, lienzos, barbacanas. En 1429-30 sobre todo, trabajos de reparación de los adarves. 
nes militares, las máquinas de guerra, especialmente las de sitio, que la municipalidad hizo fabricar en diferentes ocasiones, en particular un engeno en 1392 (10), tres mantas, cinco escalas y una gata en 1407 (11).

El Concejo efectuaba también trabajos de conservación y de reparación de los edificios civiles comunales: Casa de la Corte, Casa de la Cárcel (11 bis). Se contentaba, la mayor parte del tiempo, con hacerlas realizar en casos de necesidad extrema, aunque de la manera más sumaria - lo que hacía que dichos edificios estaban en reparación casi permanente- pues no disponía más que de escasos recursos, absorbidos éstos por los gastos de funcionamiento incomprensibles, por los impuestos reales y por los gastos militares, en los cuales estaban comprendidos los del cuidado de las fortificaciones (12). El Concejo no poseía los medios de cuidar por el buen estado de las calles y de las plazas (13), y aún menos de edificar construcciones destinadas a procurar un mayor bienestar a los habitantes y a embellecer la ciudad. Cuando un puente o un pozo amenazaban ruina, y que los usuarios exponían a los magistrados la gran pérdida que su derrumbamiento significaría, el Concejo se contentaba con suministrar los materiales necesarios para la reparación a aquellos que aceptaban encargarse benévolamente del trabajo (14). En la ciudad, los edificios en ruinas o en mal estado no eran reparados más que por aquellos a quienes la Municipalidad se los daba (15).

(10) A.C.C.M. 1391-92, fols. 72 r. $-84 v:$.

(11) A.C.C.M. 1407-08, en quinze días del 9 al 24 de octubre.

(11 bis) Ejemplos: A.C.C.M. 2 y 16 de julio 1407; A.C.-L.O. 22 de septiem. bre 1408, 13 de agosto 1409,12 de diciembre 1412, diciembre 1426, etc. A. C. - C. M. 1426-27: $14.931 \mathrm{~m}$. para la Casa de la Corte.

(12) D. MENJOT: "Finances et fiscalité municipales ordinaires à Murcie au bas Moyen-Age (fin XIV'-mil. XV siècles)», en Annales de la Faculté de Lettres de Nice, 1978.

(13) Las autoridades de Lille y Douai lo hacen. G. EsPINAs: Les finances de la commune de Douai.

(14) Ejemplos: A.C.-L. O. 8 de septiembre 1408, el Concejo dio 10 cahíces de cal para reparar el pozo de $S$. Pedro, otros 10 para adobar el puerto del puente de Tiñosa; 22 de octubre 1409 y 24 de mayo 1410, nuevo reparo del puente del puerto de Tiñosa (!).

(15) Ejemplos: 28 de diciembre de 1406, la torre de los pellegeros a Gonzalo Ferrández, molinero. El 6 de julio 1409, la misma torre a Juan de Oviedo, el Concejo paga los reparos. 
La ciudad prestaba, sin embargo, especial atención a su patrimonio económico, principalmente fuera de los períodos de alerta y de importantes presiones fiscales, en particular por lo que respecta a los molinos del Segura, aunque también se preocupara del almudin y del área de trilla (16). Las acequias y los malecones, los azudes y los escorredores de la Huerta, cuya conservación en buen estado era vital, eran objeto de frecuentes trabajos para reparar los daños causados por las inundacio. nes devastadoras. Ignoramos el coste y la mano de obra empleada, pues la Huerta poseía una administración y finanzas propias de las cuales no se ha conservado ninguna cuenta detallada.

La paz civil, que volvió por fin en 1399 , permitió la realización de proyectos de mayor envergadura. Así, vemos iniciarse la gran obra del nuevo puente, construcción en piedra con un solo arco que reemplazaba el puente de madera frecuentemente deteriorado por las crecidas del Segura (17). Anteriormente había sido edificada la puerta del puente como consecuencia de la construcción, entre 1404 y 1406, del nuevo Alcázar por orden de Enrique III.

De nada serviría identificar estos múltiples trabajos en los Libros de Ordenaciones. La lista seria larga pero poco significativa, puesto que ni su importancia, ni su duración y aún menos el número de asalariados estaban indicados. Las cinco cuentas nos ofrecen cinco ejemplos sobre las sumas que la ciudad les consagraba anualmente. No se trata más que de casos particulares. Ninguna de ellas las abarca todas; faltan la mayor parte de las sumas destinadas a la Huerta, y las que, entre $1407 \mathrm{y}$ 1408 , fueron destinadas a las murallas, puesto que eran objeto de una contabilidad especial. Entre 1407 y 1408 y 1429 y 1430 son muy limitadas a causa de las necesidades militares. A pesar de todo, lo que representan,

(16) Ejemplos: en 1395, construcción y en 1406 reparos de los molinos nuevos de allende el río. A.C.C.M. 4 de agosto 1407, reparos de los casones de la farina. A.C.-L. O. 2 de abril 1407 y 30 de agosto 1412, reparos del almodín de la farina. Reparos de la era a fines de 1408 . A. C. -7 de julio 1403 y 1407 , reparos del azud, etc... 
aunque sea mínimo, no es nunca insignificante, y a veces es impor. tante (17 bis).

Las obras públicas no son la única fuente de trabajo para los trabajadores de la construcción. En el sector privado se produce también un considerable auge a partir de principios del siglo xv. Las obras de la Catedral se inician de hecho en ese periodo. No queda, sin embargo, ningún rasgo contable (18). Numerosas casas particulares son construidas o reconstruidas en los numerosos solares que el Concejo ha distribuido generosamente y en gran número, principalmente en las parroquias periféricas que más habían sufrido a causa de la peste, a particulares, emigrantes sobre todo, que habian hecho la demanda (19). Pero se trata, lo más a menudo, de beneficiarios que reconstruyen o edifican por sí mismos, o cuando menos en gran parte, su propia casa.

Finalmente, la construcción ocupa un lugar suficientemente importante en Murcia para que, las consideraciones que podemos hacer acerca de quienes en ella trabajan, sean algo más que mera anécdota, sin que, a pesar de todo, podamos considerar sus salarios como un termómetro de la economía, puesto que no se trata, en la mayor parte de los casos, más que de pequeñas obras e incluso de minúsculos trabajos, para los que bastan pocos obreros especializados ayudados por un complemiento de mano de obra cuyos efectivos varian según las necesidades.

Èn efecto, el cuadro número I muestra que, en las dos obras más importantes que se conocen hay pocos asalariados, de 4 a 8 hombres solamente de media, y que, como en todas partes, el trabajo posee una característica sobresaliente, a saber, la irregularidad que se traduce en forma de continuas variaciones en el número de trabajadores; variacio-

(17) A.C. - L. O. 17 de mayo 1416.

(17 bis) Cf. Anejo I y II.

(18) J. TORRES-Fontes: Las obras de la catedral de Murcia en el siglo xv y sus maestros mayores; Murcia, 1969.

(19) Casi una centena en aquellos cuarenta años. 
nes diarias entre 1 y 11 , y entre 2 y 22 en 1392, y entre 1 y 13 en 1429-30. Es raro encontrar continuamente, y durante varios días, el mismo número de trabajadores: durante la fabricación del engeno, que duró sesenta y ocho días, una situación de esta índole no se presenta más que cinco veces durante dos días seguidos, una vez durante cuatro días y una vez durante tres días. De ochenta y siete días que duraron los trabajos de la madera, los treinta y cinco días durante los cuales cuatro artesanos trabajan en la obra, se distribuyen en nueve períodos diferentes, cuatro de un día, uno de dos días, uno de cuatro días, uno de siete días y dos de nueve días.

\section{Cuanro I}

\section{EFECTIVOS DIARIOS DE LA MANO DE OBRA EN UNA OBRA}

(comprende todas las profesiones y calificaciones)

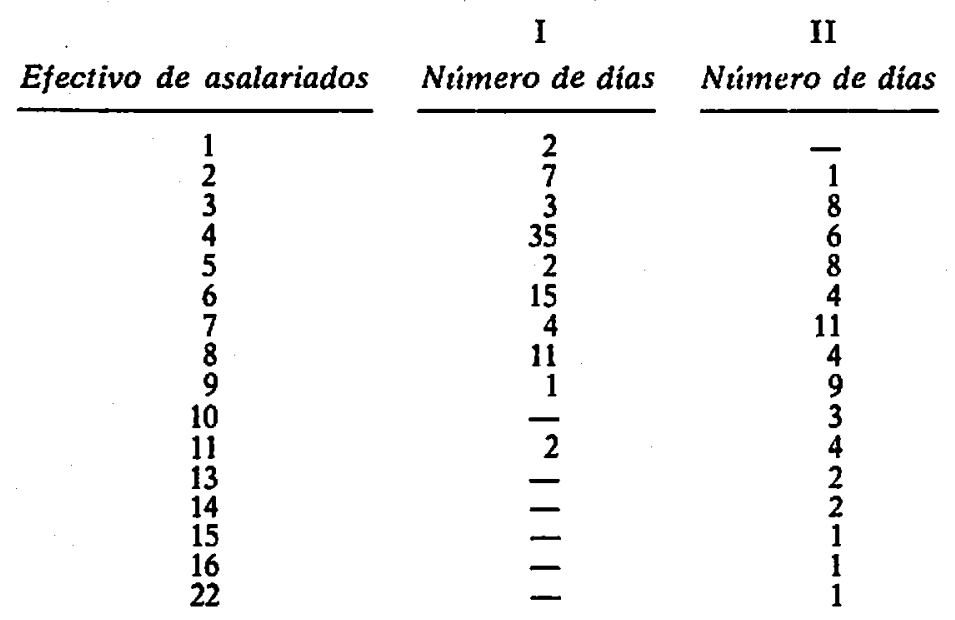

I - Labores de madera. 12 de enero-18 de junio de 1392. Fuentes: C. M., fol. 51r.-65\% -

II - Construcción de un engeno. 6 de marzo-22 de junio. Fuentes: C. M., fol. 72r. ${ }^{\circ}-84 v .9$. He contado los que fueron alquilador a tirar el carro. 
Los efectivos del conjunto de los oficios de la construcción de estas obras no superan, aun añadiendo los artesanos que no trabajan direc. tamente sino que fabrican sólo algunas piezas, la cincuentena, tanto en 1391-1392 como en 1429-1430, registros éstos en los cuales encontramos el mayor número de trabajos. Contrariamente a lo que ocurre en Sevilla no encontramos ninguna mujer (20), aunque sí judíos y moros (21), los cuales no efectúan únicamente las tareas más bajas, sino que trabajan omo carpinteros o como herreros. Carpinteros y albañiles ocupan una posición preponderante. Las profesiones de la madera son con mucho las más importantes en 1391-92, puesto que las reparaciones de puertas predominan.

\section{CUADRO II}

EFECTIVOS DE TRABAJADORES EN LAS OBRAS PUBLICAS SEGUN LAS CUENTAS

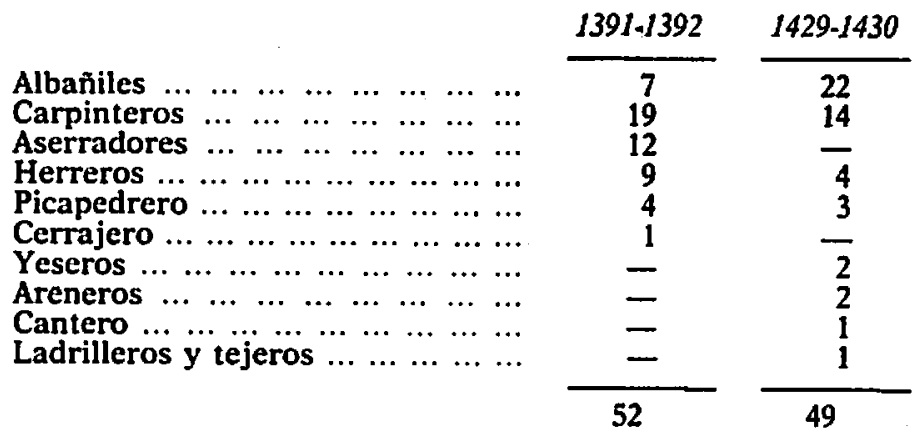

No todos los artesanos aparecen en las cuentas, sobre todo porque en las pequeñas obras, cuyos gastos quedan reflejados en aquellas, no hay necesidad de todas las profesiones. Hay trabajadores de la construcción que no trabajan, en el espacio de un año, para el sector público. Es muy posible que la construcción privada y las reparaciones de la

(20) A. Collantes de Terá Sánchez: Op. cit., pág. 335.

(21) Entre otros, en 1391-92, Yahuda judío manobre, Mahomat carpentero y su fijo Cad, Or... herrero moro. En 1426-27, Abraim herrero moro. En 1429-30, Yuçaf carpentero. 
Huerta basten para dar trabajo a algunos. Hay otros que aparecen en los Libros de Ordenaciones. ¿Cuántos son? No muy numerosos. No más, en todo caso, que los empleados por la ciudad. En 1394, la asamblea de los maestros-carpinteros reunió doce miembros. Murcia carece de artesanos calificados. En 1377, no habría habido más que un solo carpintero capaz de adobar el puente, y el Concejo aceptó adelantarle 700 maravedís de los 1.700 que había convenido en darle (22). A varios de entre ellos, las autoridades les hacen favores: ayudas financieras, dones de solares, en vista de conservarlos o de atraerlos (23). Los efectivos de trabajadores no calificados son muy variables pues la demanda es irregular, la oferta elástica. La mano de obra está acaparada por la agricultura y sus necesidades, sobre todo en el periodo en el que tienen lugar los grandes trabajos agrícolas de la Huerta. Así pues, cuando la construcción del Alcázar Nuevo, dado que las necesidades agrícolas mobilizaron toda la mano de obra de la capital, se hizo venir a los moros del Valle de Ricote, de Campos y de Albudeite (24). Para gran parte de los murcianos, las obras públicas no representaban más que un salario complementario cuando el trabajo agrícola lo permitía. Esto explica en gran parte las variaciones diarias, que no se debían en Murcia a las condiciones climatológicas, y asimismo explica el gran número de ayudantes contratados para efectuar una tarea. Treinta y dos personas fueron contratadas así en 1392 cuando se construyó un engeno, y dieciséis de entre ellas por tirar el carro.

A lo sumo, pues, podría haber habido en Murcia cerca de cien asalariados de la construcción, es decir, aproximadamente 4 a 5 por 100 de la población activa . Dicho porcentaje es bastante similar al de otras ciuda-

(22) A. C. - L. O. 28 de agosto 1377.

(23) Ejemplos A.C.-L.O. 12 de marzo 1393 donación del solar de la puerta del Alcázar a Johan Ibáñez maestro-carpentero. A.C.- L. O. 12 enero 1381, el Concejo ayuda a Domingo Ferrández, calero. Vecinos nuevos: Gínes Pérez carpentero, 13 de mayo 1398. Pedro Pérez carpentero 21 de octubre 1402, Francisco Sánchez albañil 20 de diciembre 1395. En 1429-30. Ramón Cantero recibe 100 maravedís, Maestre Felipe carpentero 300.

(24) J. Frutos-BaEza: Bosquejo Histórico de Murcia y su Concejo, Murcia, 1934, cap. X. 
des: 5 a 10 por 100 , en Brujas durante el siglo $\mathrm{xv}(25) ; 7,7$ por 100 , en Paris hacia 1290 (26); 5,8 por 100, en Nuremberg en 1393 (27); 3,8 y 3 por 100, en Sevilla en 1384 y en 1426-1451 (27 bis). Un pequeño núcleo de profesionales asistido por algunos manobras calificados y ayudantes ocasionales.

CUAdro III

EFECTIVOS COMPARADOS DE MAESTROS, MANOBRAS Y AYUDANTES EN LAS OBRAS PUBLICAS

\begin{tabular}{|c|c|c|c|c|}
\hline \multirow[b]{2}{*}{$\begin{array}{llllll}\text { Maestros } & \ldots & \ldots & \ldots & \ldots & \ldots \\
\text { Manobras } & \ldots & \ldots & \ldots & \ldots & \ldots \\
\text { Ayudantes } & \ldots & \ldots & \ldots & \ldots \\
\text { Manobras } & \mathbf{y} & \text { ayudantes. }\end{array}$} & \multicolumn{2}{|c|}{$1391-1392$} & \multicolumn{2}{|c|}{$1429-1430$} \\
\hline & $\begin{array}{l}4 \\
28\left({ }^{*}\right) \\
27\end{array}$ & $\begin{array}{r}6,8 \% \\
47,5 \% \\
45,7 \%\end{array}$ & 8 & $25 \%$ \\
\hline & & & 32 & \\
\hline
\end{tabular}

\section{II) LA ORGANIZACION DEL TRABAJO}

En prácticamente todas las ciudades de Europa occidental, la mayoría de los oficios se organizan, desde el siglo XIII hasta el siglo xv (28), de una manera progresiva, más o menos pronto y con particularidades propias, según las regiones y las ciudades, puesto que se trata de instituciones que reflejan las relaciones de fuerza que difieren según esas mismas regiones y ciudades. El problema de la organización gremial ha dado lugar en Castilla a opiniones contradictorias muy radicales. Para unos, dicha organización aparece a partir del siglo xIII (29), para otros

(25) J. P. Sosson: Op. cit., p. 220.

(26) J. DEMEY: «De handarbeiders», en Flandria Nostra, 1. 1, 1957, págs. 196-197.

(27) A. Fanfani: Storia economica, t. I. Turín, 1961, pág. 299.

(27 bis) A. Collantes de TeRÁN Sánchez: Op. cit., págs. 337, 156, 163.

(28) S. L. THRUPP: «The Gilds», en The Cambridge Economic History of El1rope, t. III, Cambridge, 1963.

(29) J. DE Contreras (Marqués de Lozoya): Los gremios españoles, Madrid, 1944. 
no lo hace antes del reinado de los Reyes Católicos (30). Otros, aún, ven en ella un tipo híbrido (31). Es evidente que la pobreza de los documentos facilita las interpretaciones, pero hay que tener en cuenta también en este sentido el mal planteamiento del problema, salvo en algunos autores como P. IRADIEL (32). Me parece como completamente erróneo juzgar la organización de los diferentes oficios en Castilla relacionándola con la de otras regiones, asi como buscar en qué fecha aparece la organización corporativa que conocemos en el siglo xvi. No hay ningún modelo perfecto ni clásico, sino únicamente un modelo dominante. Asimismo, efectuar un estudio jurídico para comprender la significación de una institución, sin situarlo en el marco socio-económico que le ha engendrado, no nos parece suficiente. La organización de los oficios es característica del trabajo urbano, hasta tal punto que se ha podido hablar "de un modo de producción corporativo" (33). Es necesario saber a partir de qué época los trabajadores de una misma profesión se organizan, asi como saber el desarrollo y la intensificación de esta organización. En nuestro caso, me limitaré a la situación de los carpinteros y de los albañiles, puesto que son las únicas profesiones de la construcción cuyos estatutos poseemos respectivamente en 1394 y en 1401. El texto de éste último está, desgraciadamente, incompleto (34).

Estos estatutos tienen como objetivo regir las condiciones de acce-

(30) J. Vicens Vives: Historia Económica de España, Barcelona, 1959: «No puede utilizarse para la Castilla bajo medieval la palabra gremios con el mismo peso específico que en la Corona de Aragón y el resto de Europa». S. Sobreoves. VIDAL: Historia de España y América, dir. por J. VICENS VIVES, t. II, Barcelona, 1961, pág. 300: «Los gremios no existen en la Castilla bajo medieval hasta el reinado de los Reyes Católicos». Tesis demostrada en Carmona, M. GonzÁlez JIMénez: El Concejo de Carmona a fines de la Edad Media, Sevilla, 1973, pág. 65.

(31) A. RUMEU DE ARMAS: Historia de la previsión social en España. Cofradias, Gremios, Hermandades, Montepios, Madrid, 1944, habla de acofradía gremial».

(32) P. IRADIEL MURUGARREN: Evolución de la industria textil castellana en los siglos $X I I I-X V I$. Salamanca, 1974, págs. 71-77, págs. 145-167.

(33) S. LATouchE: aEpistémologie et Economie», en Anthropos, citado por Y. BAREL: La ville médiévale, 1977, pág. 270.

(34) Ordenanzas de los carpenteros, A.C.- L. O. 20 de octubre 1394, apendice documental I. Ordenanzas de los albañiles, A.C.-L. O. 17 de diciembre 1401, apéndice documental II. 
so a la maestría, organizar la jurisdicción interna y profesional y precisar las reglas de fabricación y las condiciones de construcción en la ciudad. Fueron redactados, cuando menos el de los carpinteros, por los maestros de la profesión reunidos en una asamblea, los cuales los sometieron a la apreciación del Concejo quien los proclamó una vez los hubo: «visto e corregido e hemendado», puesto que aal dicho concejo, oficiales e omnes buenos de la dicha cibdat de Murcia se pertenece de procurar e ordenar la pro publica e comuna de todos los vecinos e moradores de la cibdat asi en razon de los oficios, artes e menesteres como de otros qualesquier por que todos viven en justicia e en verdad... e cada uno use bien e lealmente en el dicho oficio.... (35). Encontramos en dicho texto, como en cualquier reglamento corporativo, la exigencia de un trabajo abien e leal», es decir perfecto técnicamente y honesto moralmente, en la medida en que es conforme a las reglas del oficio, y a fin de dar plena satisfacción al comprador y de mantener el honor de la profesión.

¿En qué medida enmendaban las autoridades los estatutos antes de proclamarlos? Lo ignoramos. Dichos estatutos son seguramente el resultado de un compromiso, puesto que, cuando el Concejo quiso hacer unilateralmente «ordenaciones e cosas nuevas» en 1408, los albañiles no las aceptaron e hicieron las suyas, lo que acarreó un grave conflicto (36). De todas formas, estos reglamentos internos, una vez aprobados, promulgados y pregonados por los poderes públicos, adquieren fuerza de ley y obligan a todos los artesanos que ejercen la profesión a acatarlos.

Estos estatutos precisan las normas de fabricación para garantizar y mejorar la calidad del producto. Así, por ejemplo, para que la madera esté bien seca y trabaje menos, se exige que sea cortada entre octubre y diciembre, la de los árboles con hojas perennes durante la luna

(35) Ordenanzas de los texedores, payres e tintoreros, A.C.-L.O. 29 de ene(36) A.C. - L. O. 4 de agosto 1408. 
creciente, la de los árboles con hojas caducas durante la luna menguante. Exigencias que no son válidas cuando de lo que se trata es de fabricar las piezas de recambio que son necesarias para reparar los molinos y los ararios.

Las normas de construcción a las cuales los albañiles deben obedecer son muy minuciosas. No deben estorbar en la vía pública más de treinta días; no pueden modificar la altura de los canales para que las cantidades de agua disponible para la irrigación no varie. Por medio de medidas tales como la obligación de reconstruir los edificios de ciertas calles cediendo espacio para que éstas sean más anchas, las autoridades quieren reestructurar el espacio urbano -como hoy en día por medio de los permisos para construir-y modificar la morfología heredada de la época árabe, la cual, con el callejón de una sola entrada, ahabia privatizado el espacio» (37). Asimismo, quieren evitar las diferencias que podrian surgir entre los propietarios vecinos, reglamentando los trabajos que uno solo puede emprender.

La autorización para ejercer, no depende del pago de ningún derecho. Basta con haber sido examinado y reconocido apto por los jurados de resultas de un examen, para el cual no es necesario pagar derechos de inscripción, y que consiste seguramente en efectuar algunos trabajos, para poder instalarse por su cuenta. Esta autorización no es, para quienes ya están instalados, un medio para librarse de los nuevos artesanos - aunque en caso de dificultades pueda llegar a serlo- sino simplemente un medio para impedir que incapaces sin ninguna formación puedan ejercer el oficio. Como faltan artesanos calificados, la autorización es acordada con facilidad. De los doce maestros carpinteros que se juntaron en septiembre de 1394, tres ya habían trabajado como tales en una obra pública en 1392, y seis habían trabajado como manobras ( 37 bis). Por lo que respecta a los maestros albañiles, la disposición

(37) F. Chueca GoItia: Breve historia del urbanismo, Madrid, 1970, encontramos un sistema análogo en Génova, J. HeErs: Le clan familial au Moyen-Age, París, 1974.

( 37 bis) ¿No hay sin embargo dominio de algunas familias sobre el oficio? 
reconoce que hay artesanos insuficientemente formados que tendrán que pedir consejo a los jurados del oficio, lo que es una buena prueba de que si el ejercicio del oficio de albañil se encontraba sometido a un examen aunque no tengamos la prueba formal de ello- los jurados no son demasiado exigentes, puesto que hay carencia de artesanos frente a las necesidades acuciantes, lo que puede explicar también en parte la trecuente presencia de los mismos maestros en las diferentes obras; éstos son una élite de artesanos verdaderamente competentes en el seno de un grupo que era, en principio, calificado.

No aparecen, como en la mayor parte de las ciudades europeas, estructuras muy jerarquizadas de aprendices, oficiales y maestros. No se distinguen, de hecho, más que dos categorías de trabajadores; por un lado, los maestros, obreros especializados; por otro lado, los manobras entre los cuales encontramos los aprendices y ayudantes ocasionales. Tenemos que darnos cuenta, aunque no convenga obcecarse con los términos que designan a los trabajadores, cualesquiera que sean, pues la precisión de las palabras así como la de las cifras no posee demasiada importancia para los hombres de la Edad Media, que en 1391-1392 encontramos hombres calificados simplemente como carpinteros, mientras que, más adelante, no habrá más que maestros-carpinteros y manobras-carpinteros.

El aprendizaje no estaba organizado; su duración no estaba reglamentada, y no era necesario haber pesado por él para convertirse en maestro. El número de aprendices que cada maestro puede tener junto a él es libre. Muchos manobras tienen, pues, que aprender el oficio por la práctica. Todas estas ausencias muestran, por si era necesario recalcarlo, la escasez de mano de obra en la capital.

Estos estatutos precisan también las obligaciones respectivas del patrono y del empleado, y su objetivo consiste en moralizar sus relaciones. El maestro tendrá que terminar el trabajo que ha comenzado antes de iniciar otro, y será el responsable de los posibles destrozos, 
así como de los retrasos. A su vez, quien le encarga el trabajo tendrá que pagarle, so pena de boicoteo por parte de los otros maestros e incluso de embargo por parte de los jurados competentes, y además tendrá que procurarle buenos materiales.

A fin de luchar contra la competencia desleal y para evitar los conflictos entre artesanos, se prohíbe a los maestros que acaben el trabajo comenzado por uno de ellos sin el permiso de éste último. Pero las normas de fabricación, $y$, por consiguiente, el trabajo de cada oficio, no están determinadas con precisión, lo que es la prueba de que había seguramente trabajo para todos y que la especialización no era llevada a sus últimos extremos.

La vigilancia de los artesanos y la aplicación de este reglamento tenían necesidad, en cada oficio, de un organismo de control especial, jurados o veedores, controladores bajo juramento, cuyo objetivo era de evitar que dichas tareas no recayeran también sobre las espaldas del almotacen encargado de la policía económica (38). Estos personajes, que se encargan de dicho control especial, y que son los más importantes del gremio, nos son conocidos gracias a los estatutos de los carpinteros. Como en la industria textil (39), sus funciones principales consistían en examinar a los candidatos que pasaban el examen de maestría y en visitar a los obradores una vez al mes cuando más, mientras que por su parte los jurados de los albañiles tienen que visitar dos veces al año las paredes, aleras e cerramientos de cámaras. Además, tenían la autorización de embargar y de multar a quienes no pagaban a los maestros que habian contratado, así como de convocar anualmente a una asamblea general de los maestros para efectuar la elección de sus sucesores. Estos cargos, delicados, no parecen ser demasiado pesados, dado el pequeño número de profesionales que hay que vigilar. No eran

(38) P. Chalmeta Gendrón: aLa figura del almotacén en los fueros y su semejanza con el zabazoque hispano-musulmán», en Revista de la Universidad de Madrid, 1970.

(39) P. Iradiel Murugarren: Op. cit., pág. 160-163. 
cargos lucrativos, puesto que los veedores no recibían más que el producto de las multas que ponian, multas que eran a menudo de sesenta maravedís, aunque hay que tener en cuenta que los veedores de los albañiles se repartían el importe de las multas con el almotacen; además no cobraban nada por el trabajo de inspección, ni tampoco por el de examinar. Ser veedor no tenía, pues, nada de llamativo, y no es extraño, por lo tanto, que se castigue duramente a quien rechaza el cargo, así como la más mínima injuria que se les pueda hacer en el ejercicio de sus funciones. Podemos constatar, sin embargo, que existe una acumulación relativa de las funciones ( 39 bis). La falta de artesanos califica. dos no basta para explicar el hecho. ¿Se trata acaso de maestros que, dado que su empresa funciona bien, tienen más tiempo?; ¿o quizás, qué consideran el oficio como un deber?; ¿existen, acaso, ventajas importantes como la de la adjudicación de las obras públicas?

El cargo de veedor era anual, y su renovación debía de tener lugar diez días después de pasado San Juan entre los carpinteros, pero sólo tres días después entre los albañiles. Eran elegidos de entre los «omnes buenos sabidores del oficio» por los veedores cesantes en el ramo de la construcción; al contrario, era la asamblea de maestros quien los elegía en el ramo de la carpintería; asamblea en la que la presencia era obligatoria so pena de sanciones. Pero esta elección era una novedad de la última década del siglo xIv. Hasta ese momento, habían sido desig. nados directamente por los jurados de la ciudad ante los cuales prestaban juramento. Origen que explica el que a cada elección consular corresponda una renovación de los veedores.

Los veedores del ramo de los carpinteros, cuando examinaban a los candidatos a la profesión y cuando era necesario al controlar un producto, a fin de limitar la parcialidad de la decisión y para darle más

(39 bis) Martin de Calatayud, veedor de los carpenteros en 1394-95, 1395-96, 1398-99, 1403.1404. Miguel de Calatayud en 1398-99, 1403-1404. Miguel García, veedor de los albañiles en 1374-75, 1375-76, 1392-1393, 1395-1396. 
peso a ésta, estaban asistidos por los acompañados (40). Estos personajes, de los cuales ignoramos el número, servían quizás, como en la industria textil conquense, "de intermediarios entre veedores y menestrales cuando ambas partes no llegaban a un acuerdo. En cierta medida, rebajaban las atribuciones incontroladas de los veedores..." (41).

En definitiva, en los años 1400, los carpinteros y los albañiles murcianos no son únicamente elementos de la población murciana, que se individualizan mediante el ejercicio de una profesión determinada cuyas normas de fabricación, condiciones de trabajo, calidad y precios de fabricación, son fijados por las disposiciones de los fueros y por las medidas adoptadas por las asambleas y por los magistrados en forma de posturas y de cotos. Están organizados en gremios, que ya han superado, sobre todo los carpinteros, la situación ade una incipiente asociación... sin una estructura jurídica, económica o laboral determinada» (42). Pero, a pesar de todo, permanecen aún bajo la tutela de las autoridades que conservan un derecho de intervención en los estatutos. En principio, no puede haber oficio organizado si el Concejo se opone. No tienen ningún papel en la vida de la comunidad urbana, ni en la guardia de las puertas y de las murallas, ni en la repartición del impuesto. Tampoco tienen ningún papel político. El jurado -o los dos jurados en ciertos momentos- que representa teóricamente a los artesanos en el Concejo, no es elegido por ellos, sino que es nombrado cada año por los regidores y por los oficiales cesantes. Sus actividades caritativas y piadosas nos son prácticamente desconocidas. No parecen tener una personalidad civil y jurídica propias (43).

Los gremios de los carpinteros y de los albañiles, como los de los

(40) Los acompañados existen también en el oficio de los texedores en 1384-1385. A. C. - L. O. 26 de junio 1384 .

(41) P. Iradiel MurugarRen: Op. cit., p. 163.

(42) J. VICENS VIVEs: Historia Económica..., op. cit., p. 239.

(43) Estoy conforme con lo que dice P. Iradiel Murugarren, op. cit.: cque la constitución de un oficio como gremio equivalía, de hecho, a poder nombrar veedores y promulgar ordenanzas técnicas reconocidas por el Concejo de la ciudadx. 
oficios textiles, no tienen pues todas las caracteristicas de las jurandas del norte de Europa (44). Su organización no es, a pesar de ello, incompleta. Refleja perfectamente la situación económica murciana y las relaciones de fuerza que existian en la ciudad; relaciones que son muy diferentes de las de las ciudades flamencas. En éstas, percibimos bien las manifestaciones institucionales de sus variaciones. El partido que gana modifica, o más bien completa, en función de sus intereses, estos dispositivos no económicos de control de la producción que son las corporaciones.

Percibımos una doble evolución en el estatuto de los oficios, que se convierten en el «instrumento de los maestros» (45). Por un lado, un bloqueo de las profesiones debido a la agravación de las condiciones de acceso a la maestría, lo que conduce a la introducción, para los que no son hijos de maestro, puesto que los herederos de éstos se benefician con una dispensa o reducción, de un obstáculo fiscal y financiero: elevación regular de los derechos de inscripción; obligación de dar una fianza y de hacer una obra maestra que no era tan difícil como costosa a realizar. Por otro lado, una lucha a todos los niveles contra la concentración de los medios de producción en manos de una minoría, lo que se traduce en una serie de medidas cuyos objetivos son de precisar con gran exactitud los modos de fabricación, de impedir el acaparamiento de la mano de obra, de limitar las compras de materias primas y, en la práctica, en una igualación de los salarios.

Este oficio, que está jerarquizado de una manera estricta, que es monopolista, que no encontramos únicamente en las ciudades flamencas sino que se difunde progresivamente a lo largo del siglo xIV y sobre todo del siglo $\mathrm{xv}$ por los países franceses, inclusive por el Languedoc, que durante mucho tiempo fue reacio a ese tipo de profesión (46), cons-

(44) E. Coornaert: Les corporations en France, Paris, 1942. E. Martin SAint LBON: Histoire des corporations de métiers depuis leurs origines jusqu'd leur suppression en 1791 .

(45) H. HAUSER: Les débuts du capitalisme, Paris, 1927, pág. 179.

(46) A. Gouron: La réglamentation des métiers en Languedoc, Genève, 1958. 
tituye la respuesta de los maestros a las dificultades que conocen. Para paliar la crisis y mantener su posición social, intentan reservarse la maestría para ellos, y pretenden impedir la expansión de algunos, prohibiendo cualquier iniciativa y uniformizando el rendimiento de la mano de obra. Imponen la estabilidad, «erigen la mediocridad en idealn.

Los maestros murcianos no hacen prueba de un exclusivismo de esta índole puesto que, en la medida en que no hay competencia, no sienten la necesidad de protegerse. El pleno empleo parece estar garantizado. Falta mano de obra. Por otra parte, poco numerosos en una ciudad en la que dominan cuantitativamente los trabajadores agrícolas y políticamente una oligarquía de propietarios de tierras y de rebaños, los artesanos no han podido emanciparse totalmente de la tutela del Concejo como sus colegas flamencos, quienes han conseguido hacerlo durante el período de desorden que agitó la región a finales del siglo XIII, puesto que no hay que olvidar que "la verdadera organización corporativa es una creación revolucionaria» (47), por lo que los oficios murcianos de los años 1400 se parecen mucho a los oficios flamencos del siglo XIII.

Agrupaciones que en un principio son espontáneas, son aceptadas e incluso fomentadas por los dirigentes a fin de poder controlarlas gracias a los jurados y poder garantizar a los consumidores, entre los cuales ellos mismos se cuentan, productos de perfecta calidad. No es fortuito que el estatuto de los carpinteros, en el que el oficio está mejor organizado y que posee mayor autonomía, data de 1394 cuando la ciudad está relativamente poblada antes de que la epidemia de peste produzca efectos catastróficos y sobre todo fecha en la cual, desde hace tres años, la ciudad se encuentra agitada por profundos desórdenes causados por la guerra civil entre Manueles y Fajardos. Como ocurre en Flandes un siglo antes, los oficios aprovechan esta ocasión, en la medida de sus débiles medios, para emanciparse. Las autoridades cuya base

(47) E. PERroy: Le travail dans les régions au Nord du $X I^{\circ}$ au début du XIV', C.D. U., p. 130. 
social se amplía -el número de regidores y de oficiales llega a ser de cuarenta al año-, se ven obligadas a ser menos intransigentes puesto que tienen necesidad del apoyo de toda la población. No puedo tampoco evitar de señalar que en esta fecha, en los Libros de Ordenaciones, encontramos la fórmula: "los jurados recibieron por veedores», fórmula que iba a repetirse cada año, cuando la renovación de los veedores, junto con: "cada oficio con voluntad de los jurados pusieron por veedor del dicho oficion. Es evidente que hay que tener en cuenta que la terminología no está fijada una vez por todas, que hay registros que faltan, que en ciertos han desaparecido las páginas en las que estaban inscritos los veedores, que en otros, en fin, éstos son registrados sin que se sepa a ciencia cierta por quien han sido designados. Por consiguiente, no es quizá más que una coincidencia, pero estos años inmediatamente anteriores a la peste ven quizás una victoria del artesanado, en la medida en que los veedores se convierten en representantes de los maestros quienes los eligen a partir de ese momento, a la vez que el oficio se convierte en instrumento de protección frente a los poderes públicos.

\section{III) CONDICIONES DE TRABAJO, NIVEL DE VIDA Y PODER AD- QUISITIVO}

La irregularidad del trabajo, que ya hemos señalado anteriormente, en las obras públicas tiene como consecuencia de acentuar las desigualdades frente al empleo.

A partir de estas cifras podemos constatar que en 1391-1392, 50 por 100 de los trabajadores son contratados por la ciudad para un período menor de siete días, y cerca de $1 / 3$ para un período de un día solamente, mientras que en 1429-1430, 50 por 100 son contratados para periodos de uno a tres días. Esta desigualdad no es quizás dramática a causa de la elasticidad de la oferta de mano de obra no calificada que constituye la mayor parte de la fuerza de trabajo. En cuanto a los maestros con- 
Cuadro IV

REPARTICION ANUAL DEL EMPLEO EN LAS OBRAS URBANAS

EJERCICIO 1391-1392

EJERCICIO $1429-1430$

\begin{tabular}{|c|c|c|c|}
\hline $\begin{array}{c}\text { Jormadas de } \\
\text { salario }\end{array}$ & $\begin{array}{l}\text { Numero de } \\
\text { trabajadores }\end{array}$ & $\begin{array}{c}\text { Jornadas de } \\
\text { salario }\end{array}$ & $\begin{array}{l}\text { Numero de } \\
\text { trabajadores }\end{array}$ \\
\hline 1 & 19 & 1 & 6 \\
\hline 2 & 8 & 2 & 7 \\
\hline 3 & 4 & 3 & 4 \\
\hline 4 & 4 & 4 & 1 \\
\hline 7 & 5 & 5 & 1 \\
\hline 8 & 2 & 6 & 6 \\
\hline 9 & 2 & 7 & 2 \\
\hline 10 & 1 & 9 & 3 \\
\hline 11 & 3 & 12 & 2 \\
\hline 14 & 5 & 13 & 1 \\
\hline 15 & 1 & 14 & 1 \\
\hline 18 & 2 & 15 & 1 \\
\hline 19 & 1 & 20 & 1 \\
\hline 20 & 3 & 25 & 1 \\
\hline 34 & 1 & 29 & 1 \\
\hline 49 & 1 & 38 & 1 \\
\hline 51 & 2 & 57 & 1 \\
\hline 60 & 1 & 66 & 1 \\
\hline 65 & 1 & 68 & 1 \\
\hline 69 & 1 & & \\
\hline 63 & 2 & & \\
\hline 87 & 1 & & \\
\hline 609 & 70 & 393 & 37 \\
\hline
\end{tabular}

tinúan en el mismo trabajo durante mucho tiempo y encontramos con frecuencia a los mismos durante muchos años. Jaime Mulet aparece cada año en las cinco cuentas que se conservan; Juan Domínguez, Miguel de Calatayud, Simón Daroca en las tres primeras. 
"Los que labraren en la villa o logar que fueren alquilados que labren desde el dicho tiempo que sale el sol et dexen de labrar quando se pusiera el sol» (48). El final de la jornada a nono es una excepción. Se señala y da lugar a una remuneración inferior (49). La jornada está subidividida en dos semi-jornadas (50), pero el tiempo de trabajo es aun el de los clérigos, ritmado por los oficios religiosos (51). La campana de la misa de prima anuncia el comienzo; la del Ave María el final (52). No hay ninguna campana urbana en Murcia, y aun menos reloj mecánico. Sin embargo, aunque esta temporalidad no esté laicizada, no por ello deja de estar al origen de rudos conflictos sociales. Los trabajadores murcianos, como los otros, «luchan por ser maestros de su tiempo» (53). Así, por ejemplo, en 1408, cuando el Concejo fija los salarios máximos, los albañiles responden disminuyendo su tiempo de trabajo; el Concejo endurece su posición de resultas de ello, e impone una multa importante a quienes trabajan menos que el horario previsto (54). Los albañiles se ponen en huelga, lo que obliga a las autoridades, después de haber declarado que no tenían nada contra ellos, a aceptar que «los dichos albañiles que labren e usen de la manera que antes le solian usar...» (55), al tiempo que mantienen la tasa de los salarios, y prohíben a los que les emplean que los alimenten, lo cual era otro paliativo encontrado por los albañiles para no respetar los topes salariales (56). En 1414, el Concejo, considerando que el tiempo empleado por

(48) Ordenamiento de precios y salarios, ed. J. ToRres-FonTes: A.H.D.E., 1961, pág. 287.

(49) A.C.C.M. 21 de septiembre 1391: «Fueron alquilados dos omnes ... fasta ora de nonas.

(50) Subdivisión que se asienta en el siglo xIv. D. KNOOP y G. JoNes: Op. cit., pág. 117.

(51) J. LE GoFF: "Temps de l'église et temps du marchand" y aLe temps du travail dans la crise du XIv: du temps médiéval au temps modernew. Reed. en Pour un autre Moyen-Age, París, 1977. Murcia no es una importante ciudad textil en donde unu temps nouveau s'apesantit, le temps des drapiers celui de la domination
d'une catégorie sociale, le temps des nouveaux maîtres.

(52) A.C. - L. O. 4 de agosto 1408.

(53) J. LE GOFF: aLe temps du travail...», op. cit.

(54) A.C. - L. O. 4 de agosto 1408.

(55) Ibid. 11 de septiembre 1408 .

(56) Ibid. 24 de noviembre 1408. 
los obreros para el almuerzo en su casa constituia una pérdida demasiado pesada, intenta imponerles la fiambrera (57).

Las obras que conocemos duran demasiado poco para que podamos determinar con precisión el número de días de trabajo durante el año, y la duración del contrato es demasiado variable para poder apreciar la asiduidad de los trabajadores. Podemos constatar, sin embargo, que trabajan todos los dias, del lunes al sábado comprendido, y siguiendo el mismo horario. El salario correspondiente a este último día siendo el mismo que el de los otros, en la medida en que no se practica la $\alpha$ se. mana inglesa como en muchas otras ciudades del norte de Europa. Cuando la construcción del engeno, que principia el 6 de marzo, y para la que los trabajos principales finalizan el 28 de mayo, aparte de los once domingos, no se trabaja el 25 de marzo, el 11 y el 12 de abril, el 15, el 16, el 17 y el 25 de abril; el 1, el 3, el 8, el 9, el 10, el 20 y el 21 de mayo, es decir, veinticinco días contra cincuenta y siete de trabajo. Las labores de madera se prosiguen sin interrupción del 12 de enero al 12 de abril, salvo los doce domingos y el 2, el 3 y el 21 de febrero, el 25 de marzo, el 3, el 4, el 5, el 8 y el 11 de abril, es decir, setenta días de trabajo contra veintiún días de asueto. Hay que notar que la interrupción de la obra no corresponde forzosamente con un día de fiesta, sino a un cambio de lugar de trabajo o a un paro momentáneo debido a la necesidad de comenzar en otro lugar una urgente reparación. Así, pues, entre el 6 de marzo y el 12 de abril, en que las dos obras funcionan conjuntamente, los obreros no descansan al mismo tiempo más que dos días, el 25 de marzo que es la fiesta de la Anunciación y el 11 de abril, o sea, dos días de descanso, sin contar los domingos, contra treinta días de trabajo. Un año de 275 días de trabajo teórico parece, por lo tanto, una estimación razonable (57 bis).

(57) Ibid. 27 de enero 1414: aQue todos los omnes que viniesen a la dicha lavor que traygan ay a comer et non partan de ay fasta la ora que fueren de ir de la dicha lavorv.

(57 bis) M. Baulant: “Le salaire des ouvriers du bâtiment à Paris de 1400 à 1726x, en Ammales E.S.C., 1971, pág. 471. 
Como en otros lugares, los obreros de la construcción son remunerados a la pieza o al día. El salario diario es el modo de retribución dominante. Se da integramente en numerario puesto que, si el clavario daba una parte en comida, lo que prohíbe el Concejo, indicaría la compra de ésta a fin de justificar sus gastos, lo que ocurre una vez: el 14 de diciembre de 1429, fecha en la que da de beber al equipo de cinco albañiles que labra en la torre.

Si la remuneración de los maestros es idéntica, la de los manobras, sobre todo en 1391.1392 y en 1395-1396, y excepcionalmente en 1429-1430, conoce fluctuaciones numerosas e importantes.

CUADRO DE FRECUENCIA DE LOS SALARIOS DIARIOS DE LOS MANOBRAS $Y$ AYUDANTES (en maravedís)

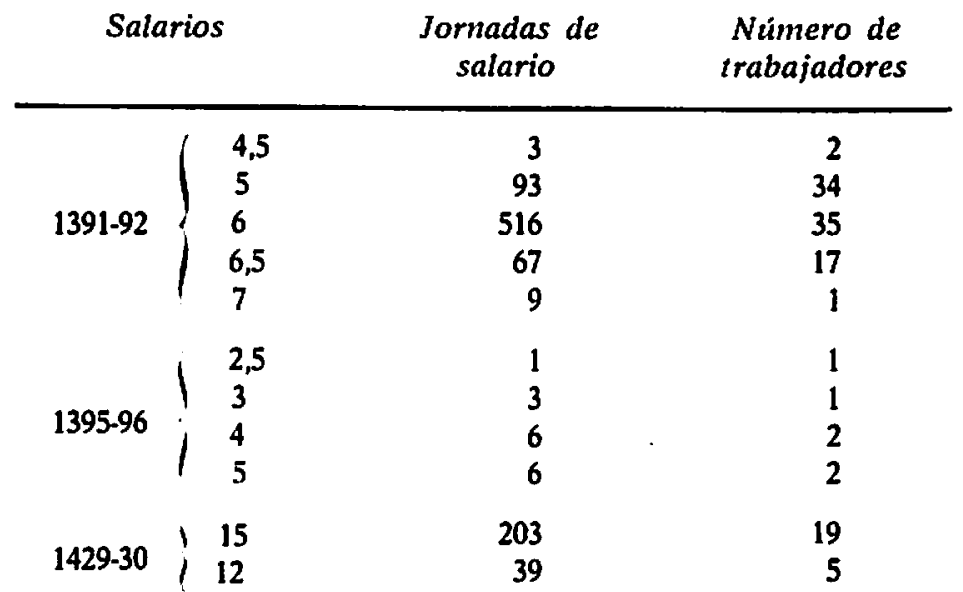

Esta diversidad no refleja variaciones de temporada de la duración de la jornada de trabajo. Si existiera un salario de verano y un salario de invierno como en muchas ciudades europeas, la remuneración de los maestros variaría también, y el Concejo indicaria en sus tasas dos ba- 
remos, o en todo caso la fecha de validez de uno de ellos, como ocurre para la tasa de las carnes.

Esta diversidad refleja esencialmente las variaciones de tareas, puesto que, muy frecuentemente, el mismo individuo es quien es remunerado diferentemente según la calificación requerida para el trabajo solicitado.

\section{CUADRO DE FRECUENCIAS DE LOS SALARIOS DE LOS MANOBRAS Y AYUDANTES EN FUNCION DEL TIPO DE TRABAJO EN EL TRANSCURSO DEL EJERCICIO 1391.1392}

\begin{tabular}{|c|c|c|c|c|}
\hline & $4,5 \mathrm{~m}$ & $5 \mathrm{~m}$ & $6 \mathrm{~m}$. & $6,5 \mathrm{~m}$. \\
\hline $\begin{array}{lllllll}\text { Para } \operatorname{aserrar} & \ldots & \ldots & \ldots & \ldots & \ldots & \ldots\end{array}$ & - & - & 125 & 66 \\
\hline Por tirar el carro $\ldots \ldots \ldots \ldots$ & - & 53 & - & - \\
\hline Por amasar el aljes $\ldots \ldots \ldots \ldots$ & 3 & - & - & - \\
\hline
\end{tabular}

Puede muy bien ser así, aunque los documentos no lo precisan, cuando un mismo manobra-albañil no recibe todos los días el mismo salario. Este es el caso de uno de ellos quien, en 1396, cobra 4 maravedís cuando «labra en el cimienton. Se alquila, pues, el trabajo que puede hacer el hombre antes que a la persona (58).

Pero, para un trabajo idéntico, puede ocurrir que dos trabajadores, y con frecuencia el mismo individuo, no reciban la misma retribución. Ya lo hemos constatado en el cuadro anterior con respecto a los aserradores, y aun es más patente con respecto a los otros manobras y ayudantes.

(58) Para R. Romano: Op. cit., pág. 494: aun des événements les plus importants de toute l'histoire économique et de l'histoire tout court (est) le passage du salaire de subsistance au salaire entendu comme rétribution d'une certaine quantité de travail fournie...v. 
CUADRO DE FRECUENCIAS DE LOS SALARIOS DIARIOS DE LOS MANOBRAS $Y$ AYUDANTES DE LOS DIFERENTES OFICIOS

\begin{tabular}{|c|c|c|c|c|}
\hline 1391-1392 & $5 \mathrm{~m}$. & $6 \mathrm{~m}$ & $6,5 \mathrm{~m}$. & $7 \mathrm{~m}$ \\
\hline $\begin{array}{llll}\text { Manobras-carpinteros } \quad \ldots & \ldots & \ldots\end{array}$ & - & 347 & 1 & - \\
\hline $\begin{array}{llllll}\text { Manobras-albañiles } & \ldots & \ldots & \ldots & \ldots\end{array}$ & 3 & 4 & - & - \\
\hline $\begin{array}{llllll}\text { Manobras.herreros } & \ldots & \ldots & \ldots & \ldots\end{array}$ & 33 & - & - & - \\
\hline $\begin{array}{llllllll}\text { Otros manobras } & \ldots & \ldots & \ldots & \ldots & \ldots\end{array}$ & 4 & 34 & - & 9 \\
\hline $1395-1396$ & $2,5 \mathrm{~m}$ & $3 m$. & $4 \mathrm{~m}$. & $5 \mathrm{~m}$. \\
\hline Manobras-albañiles & - & - & 5 & 1 \\
\hline Manobras-carpinteros $\ldots \ldots \ldots \ldots$ & - & - & - & 5 \\
\hline Ayudantes manobras - albañiles. & 1 & 3 & 1 & - \\
\hline
\end{tabular}

Estas diferencias reflejan las modificaciones de la oferta y de la demanda en el mercado de trabajo, en el que la oferta de mano de obra no-calificada es mucho más elástica que la de mano de obra calificada. «El movimiento de los salarios de estas categorías es, pues, más flexible y traduce de una forma más adecuada los períodos de escasez absoluta - relativa de la mano de obra» (59). Constatamos, en particular, que algunos salarios aumentan durante la primavera, el de los aserradores, por ejemplo, cuando los trabajos agrícolas necesitan más mano de obra que, por lo tanto, escasea en el mercado. El único asalariado que cobra 7 maravedís es contratado del 14 al 23 de junio.

Por último, algunos casos raros de trabajadores, que reciben una remuneración diferente de los otros para un trabajo aparentemente idéntico, pueden explicarse por razones especificas de difícil identificación: la edad, como, por ejemplo, el caso del hijo de Vicente Cerrajero, la fuerza muscular, la habilidad profesional, aunque entre estas razones no podamos considerar la etnie puesto que moros y judíos no están subpagados, aunque estén siempre entre los peor pagados.

(59) B. Geremek: Op. cit., pág. 569. 
Frente a esta diversidad, la identidad del salario de los maestros es característica, reflejando una jerarquía estricta e inmutable en la que el primer lugar está evidentemente ocupado por los herreros, en esta ciudad en la que el artesanado de guerra ocupa un lugar tan importante.

\section{CuAdro $\mathrm{V}$}

SALARIOS DIARIOS DE LOS MAESTROS

\begin{tabular}{|c|c|c|c|}
\hline & $1391-1392$ & $1429-1430$ & $1407-1408$ \\
\hline Herrero $\ldots \ldots \ldots \ldots \ldots$ & 10 & 22,5 & - \\
\hline Carpentero $\ldots \ldots \ldots \ldots \ldots$ & 8 & $12-16,5 \cdot 18$ & 18 \\
\hline Albañil $\ldots \ldots \ldots \ldots \ldots$ & 8 & $15-16,5$ & 18 \\
\hline $\begin{array}{llllll}\text { Picapedrero } & \ldots & \ldots & \ldots & \ldots\end{array}$ & 7 & - & 15 \\
\hline
\end{tabular}

Esto es debido, principalmente, a dos factores. En primer lugar, al juego de la oferta y de la demanda del mercado. Las dos son muy poco elásticas. La oferta es muy limitada. Los maestros, en pequeño número, pueden fácilmente entenderse para imponer una tarifa única. En segundo lugar, y quizás, sobre todo, a la reglamentación concejil que al fijar al menos a partir del siglo xv, salarios tope, semejantes para los carpinteros y para los albañiles, por un lado para los maestros y por otro para los manobras, uniformiza las remuneraciones e instaura una relación fija entre las de estas dos categorías.

¿Cuál es la evolución de los salarios? Contentémonos con determinar, en este primer enfoque, la evolución a partir de las cinco cuentas. La documentación nos obliga a ello, pues prácticamente los Libros de Ordenaciones no encierran más que excepcionalmente los salarios de trabajadores de la construcción. Es necesario dejar de lado los salarios por pieza, que no son utilizables, puesto que la mayor parte del tiempo amalgaman la remuneración del trabajo y el coste de las materias pri- 
mas utilizadas, e incluso cuando se distingue entre una y otro, la duración del trabajo varía en función del material escogido y de las dimensiones impuestas. Los salarios diarios son, por suerte, más frecuentes, pero desigualmente numerosos en función de la duración y de la importancia de las obras, más numerosos en los dos extremos del período que en los otros años. Solamente los de los carpinteros y de los albañiles figuran en las cinco cuentas. En 1391-1392, 1395-1396 y 1429-1430, he guardado, como salario tipo de los manobras, el salario modal que se impone claramente durante el primer y el último año.

El gráfico nos muestra una imagen de las fluctuaciones que, durante estos cinco años, se producen en los salarios nominales, expresados, así como en las fuentes, en moneda de cuenta. He renunciado a convertirlos en gramos de metales preciosos, no por fidelidad a los documentos, sino porque es una tarea excesivamente delicada y falaciosa, puesto que la plata era una mercancía cuyo precio, como las otras mercancías, variaba, su único interés reside en las comparaciones a escala europea que permitia.

El alza es clara. De 1391 a 1430, el salario de los maestros pasa de 8 a 18 maravedís, multiplicándose por 2,25; el de los manobras de 6 a 15, multiplicándose por 2,5. Pero dicha alza no es ni progresiva ni regular. Se pueden distinguir tres fases principales, sobre las cuales la documentación fragmentaria no permite definir ni los términos cronológicos ni la amplitud:

- una fase de estabilidad, que ha comenzado antes de 1391 y que se prosigue hasta en 1400, con, quizás, una tendencia a la disminución de los salarios de los manobras en 1395-1396, pero la insuficiencia de los datos nos impide saberlo con certeza. Así mismo, la documentación no permite tampoco observar si el retorno de la peste en 1395-1396 desorganiza el mercado del trabajo;

- una fase de alza brutal, 50 por 100 en 1400 y en 1407 y 1408, en que el salario de los maestros pasa de 12 a 16,5 maravedís, el de los ma- 
nobras de 9 a 13,5; e incluso dichos salarios máximos son superados por el Concejo, quien da hasta 18 maravedís, al mismo tiempo que los albañiles cobran a veces hasta 21 maravedís (60).

Como podíamos pensarlo, las mutaciones monetarias son responsables en gran parte de esta alza, puesto que en 1399 el maravedí que valía 3 blancas no vale más que dos. Hay que señalar, que la tasa municipal no consigue atajar el alza en el periodo de crisis de 1407-1408 en el que, a causa de la guerra abierta contra Granada, se movilizan hombres y recursos, y en el que se tiene gran necesidad de trabajadores para las murallas y para la construcción de las máquinas de sitio.

- nuevo período de estabilidad o de alza limitada, que no cesa en 1430.

Esta periodización vaga se encuentra en otras ciudades de Europa (61).

Los salarios nominales de los maestros y de los manobras siguen una evolución bastante paralela, pero la diferencia entre ellos es mucho más reducido que en numerosas ciudades tan diferentes como, por ejemplo, Tolosa, Brujas, Tours, París, en las que los primeros cobran el doble que los segundos (62). Esta diferencia tiende incluso a reducirse. Si calculamos la tensión que existe entre el salario del maestro y el del oficial tomando el salario del maestro como si valiera 100 por 100, constatamos que siempre es débil y que acusa una tendencia a la baja: es de 25 por 100 en 1391-1392, de 18,2 por 100 en $1407-1408$ y de 16,7

(60) Fijación de los salarios, A.C.- L. O. 13 de julio 1408: maestros, 11 maravedís de 3 blancas el maravedí; manobres: 9 maravedís; llamada el 4 de agosto y el 24 de noviembre 1408 (¡los albañiles tomaban entonces de jornal 14 maravedís!).

(61) Por ejemplo en Rouen, G. BoIs: La crise du féodalisme. Economie rurale et démographie en Normandie orientale du début du $X I V^{\circ}$ au milieu du $X V I^{\circ}$, París, 1976, págs. 96-97. En Bruges, J. P. Sosson: Op. cit., págs. 225.227.

(62) PH. WolfF: Commerces et marchands de Toulouse (vers 1350-vers 1450), París, 1954. J. P. Sosson: Op. cit., pág. 227. B. Ch Evalier: Tours ville royale (13561520), Paris, 1975. B. Geremek: Le salariat dans l'artisanat parisien du XIII au au XIV:, París, 1968. G. Bors: Op. cit., págs. 96-97. 


\section{GRAFICO I :}

\section{SALARIOS NOMINALES DEL SECTOR DE LA CONSTRUCCION (en maravedis)}

- Salarios diarios de los maestros carpinteros y albañiles (albañiles sólos a partir de 1431)

- - Salarios diarios de los manobras carpinteros y albañiles (albañiles sólos a partir de 1431)

(escala semi-logaritmica)

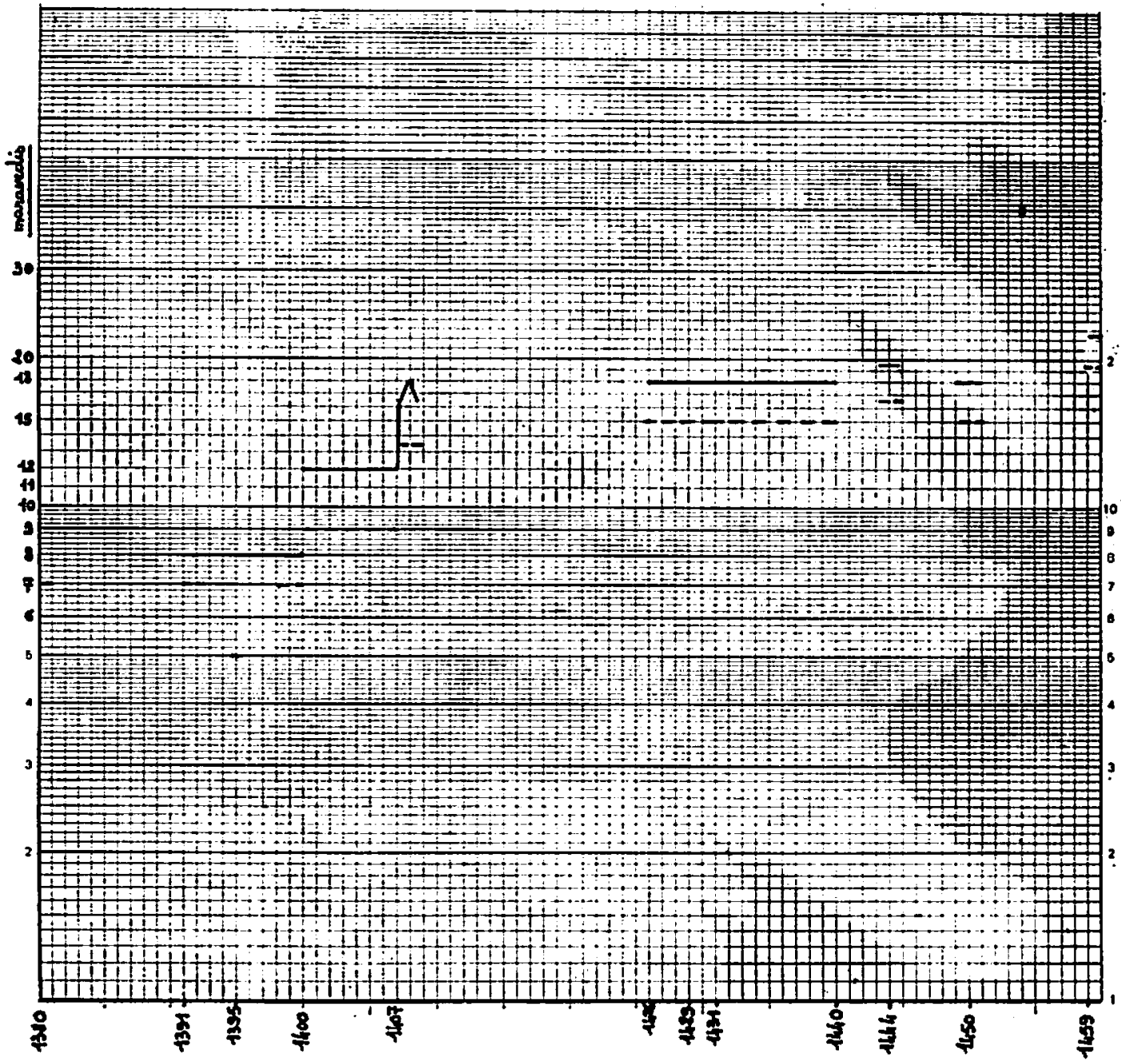


por 100 en 1426-1427 y en 1429-1430. Si calculamos el porcentaje que el salario respectivo de cada uno de ellos representa, considerando la suma de salarios del maestro y del manobra como equivalentes a 100 por 100 , percibimos débiles variaciones que corresponden a una ligera disminución de la parte perteneciente al maestro y, por lo tanto, a un crecimiento de la que pertenece a los manobras.

\begin{tabular}{|c|c|c|}
\hline Ejercicios & Maestros & Manobras \\
\hline $1391-1392 \ldots$ & $57,2 \%$ & $42,8 \%$ \\
\hline $1407-1408 \ldots \ldots \ldots$ & $57,9 \%$ & $42,1 \%$ \\
\hline $\begin{array}{cccccc}1429-1430 & \ldots & \ldots & \ldots & \ldots & \ldots\end{array}$ & $54,5 \%$ & $45,5 \%$ \\
\hline
\end{tabular}

La separación parece atenuarse ligeramente entre maestros y mano. bras. Dicha evolución es diametralmente opuesta a la que constatamos en la mayor parte de las ciudades europeas.

¿Cuál es el poder adquisitivo de estos salarios? Las dificultades y las lagunas son tan considerables, que no podemos superar la mera aproximación o la simple impresión. La historia de los precios no está aún escrita, y en todo caso es imposible sin una documentación serial. Nuestro empeño, pues, no es ese. Podemos dar únicamente una impresión, fundamentada en una escasa cosecha de datos. El fin del siglo XIV aparece como un período de precios agrícolas, trigo, cebada, vino y carne, relativamente bajos (63). El cambio de la tendencia parece situarse en el momento de pasar al siglo $x v$, a causa de la epidemia de peste $y$ de la mutación monetaria, y parece prolongarse más allá de 1430. Estas fluctuaciones coinciden con el esquema general que encontramos en todas las regiones de Europa que han sido estudiadas (64). Así, pues,

(63) Cf. anejo III.

(64) H. VAN DER WEE: The growth of the Antwerp market and the european economy, La Haye, 1963. E. J. HAMILToN: Money, prices and wages in Valencia, Aragón and Navarre, 1351-1450. Cambridge (U.S.A.), 1936. G. BoIs: Op. cit. PH. WOLFF: Op. cit. 
como ocurre con el movimiento de los salarios, e independientemente de sus aspectos particulares, un movimiento tan general no puede explicarse más que por medio de los mecanismos generales deì sistema socio-económico (65).

Incluso para apreciar el poder adquisitivo de los salarios durante los cinco años que conocemos, la tarea es muy difícil. No encontramos en los Libros de Ordenaciones y Libros de Cuentas suficientes precios alimenticios que se extiendan a lo largo de todo el año, lo que no permite, la mayor parte del tiempo, corregir sus fluctuaciones de temporada estableciendo las medias. Esta imposibilidad es particularmente nefasta por lo que se refiere a los cereales para fabricar pan, cuyos precios son particularmente sensibles a las variaciones coyunturales y que manifiestan fuertes oscilaciones de amplitud muy desigual.

Los salarios diarios calculados en términos de poder adquisitivo de trigo, de cebada, de vino (en medias anuales cuando los datos eran suficientes) y de carne son variables y parecen elevados, pero puede tratarse quizá de movimientos bruscos en una curva de la que ignoramos el trazado puesto que, si las curvas construidas a partir de medias anua. les (66): «disimulando el drama de las estaciones y de los días, pierden gran parte de su significado humanos (67), las cinco cuentas, al no permitirnos conocer más que el dicho drama, ocultan la tendencia secular. De todas maneras, cualquiera que sea su significado, la evolución no es ni progresiva, ni regular. Los accidentes son importantes, en particular en la curva de los salarios reales en trigo, producto éste muy sensible a las variaciones de la coyuntura. El equilibrio del presupuesto de

(65) Intentos de explicación, G. Bors: Op. cit., y W. KuLA: Théorie économique du système féodal. Pour un modèle de l'économie polonaise XVI'XVIII. ParisLa Haye, 1970.

(66) Los tanteos cifrados plantean importantes problemas metodológicos ex. puestos por W. KULA: Problemi e metodi di storia economica, 1963, trad. Milano, 1973.

(67) R. Gascon: Grand commerce et vie urbaine au XVI'. Lyon et ses marchands, Paris-La Haye, 1971, t. II, pág. 755. 
cada familia varia periódicamente, e incluso sin cesar. La fuerte alza de los salarios en 1407-1408 no compensa el brusco estallido de los precios, sobre todo el de los granos.

\section{CUADRO VI}

\section{PODER ADQUISITIVO DE LOS SALARIOS}

A) CaH1z de tRigo en salarios diarios

\begin{tabular}{|c|c|c|c|c|}
\hline & 1391-92 & $1395-96$ & $1407-08(*)$ & 1429.30 \\
\hline $\begin{array}{llllll}\text { Maestro } & \ldots & \ldots & \ldots & \ldots & \ldots\end{array}$ & 5 & 6,25 & 8,2 & 5 \\
\hline Manobra $\ldots \ldots \ldots \ldots$ & 6,6 & 10 & 10 & 6 \\
\hline
\end{tabular}

B) CaHIZ de CEBada EN SALARIOS diaRios

\begin{tabular}{|c|c|c|c|c|}
\hline & $1391-92$ & $1395-96$ & $1426-27\left(^{*}\right)$ & $1429.30(*)$ \\
\hline $\begin{array}{lllllll}\text { Maestro } & \ldots & \ldots & \ldots & \ldots & \ldots\end{array}$ & 2,75 & 2,50 & 3,1 & 3,7 \\
\hline $\begin{array}{llllll}\text { Manobra } & \ldots & \ldots & \ldots & \ldots & \ldots\end{array}$ & 3,6 & 4 & 3,7 & 4,5 \\
\hline
\end{tabular}

\begin{tabular}{|c|c|c|c|c|c|}
\hline & $1391-92\left(^{*}\right)$ & $1395-96(*)$ & $1407-08\left(^{*}\right)$ & $1426-27\left(^{*}\right)$ & $1429-30(*)$ \\
\hline Maestro $\ldots \ldots \ldots$ & 0,8 & 0,6 & 2 & 1,5 & 0,8 \\
\hline Manobra ... ......... & 1,1 & 0,9 & 2,4 & 1,8 & 0,97 \\
\hline
\end{tabular}

D) Poder adouisitivo de un salario diario en libra de carnero (I), cabrón (II), Y OVEJA, VACA Y CABRA (III)

\begin{tabular}{|c|c|c|c|c|c|c|c|c|c|}
\hline & \multicolumn{4}{|c|}{ 1391-92 } & \multicolumn{2}{|r|}{1395.96} & \multicolumn{3}{|c|}{$1407-08$} \\
\hline & I & II & III & I & II & III & I & II & III \\
\hline Goctro & 2,6 & 3,6 & 4 & $2,6(2,5)$ & $3,6(3,3)$ & $4,4(4)$ & 2 & 2,3 & 2,75 \\
\hline Manobra. & 2 & 2,5 & 3 & $1,6(1,5)$ & $2,3(2)$ & $2,7(2,5)$ & 1,7 & 1,9 & 2,25 \\
\hline
\end{tabular}

Entre paréntesis, de San Miguel a Carnestolendas. Precios de la carne fijados por el Concejo.

(*) Medias anuales.

\section{4}


Comparemos los salarios de los trabajadores de la construcción con las sumas desembolsadas por el Concejo para alimentar algunos personajes. Una comida excepcional, ofrecida en 1396 «a un ballestero que vino a Murcia para ir a las galeas a Cartagena», y que se compone de 2 piernas de carnero, 4 libras de vaca, 5,5 azumbres de vino, fruta y queso, arroz, especias y pan, cuesta 41 maravedis, es decir, más de cinco días de salario de un maestro, casi siete de un manobra (68). En 1427, «para llevar e dar de comer al alcalde de la mesta, al escribano, al alguazil, al pregonero que han de ir a fazer la mesta», el mayordomo compra 2,5 arrobas de farina para fazer pan, 3,5 cantaras de vino, 1 cabrito, 1 onza de pimienta, todo por un coste de 108 maravedis (69). En 1395, el clavario: adespendio en provision e mantenimiento (1/30 de fanega de trigo por persona; carne y pescado, no vino) de 3 moros que están en la prisión por prendas..." de 4 coronados a 9 dineros cada día por cada uno, durante algunos meses (70). Así, menos de un maravedí es suficiente para sobrevivir.

Un asalariado de la construcción llega pues a alimentar a su familia sin privarse demasiado. Soporta, sin embargo, regularmente una fuerte fiscalidad real y municipal, pero los numerosos solares derribados que el Concejo da le permiten alojarse a buen precio (71).

\section{CONCLUSION}

Pequeña minoría de profesionales y de manobras, organizada en gremios, que nombra sus veedores y tiene sus estatutos que precisan sobre todo las reglas de fabricación y las condiciones de acceso a la

(68) A.C. C. M. mayo 1396.

(69) A.C.C.M. 18 de enero 1427. Del primero al 26 de octubre 1429: ael dicho mayordomo para carne e pan e vino e lo que fue necesario de comer e beber para Juan Martín prisionero e a los que guardaban» despendió cada día entre 15 y 21 maravedís, un promedio de 18 maravedís. A.C.C. M. 1429-30.

(70) A.C.C.M. $1395-1396$ del mes de agosto al mes de diciembre.

(71) D. Menjot: aL'incidence sociale de la fiscalité des Trastamares de Castille au xiv siecles, en Historia, Instituciones, Documentos, 5, Sevilla, 1978. 
maestría, aun bajo la tutela de las autoridades y cuya remuneración nominal, muy variable entre los manobras, se alza mucho pero no regularmente, tales son las conclusiones más relevantes que se desprenden de estos primeros enfoques.

No podemos, sin arriesgarnos, generalizarlas a los otros trabajadores de la ciudad. Será necesario completarlos y ampliarlos. ¿Cuál es la capacidad de representación de los movimientos globales de la economía que tienen estos salarios, que son los únicos que podemos conocer y seguir groseramente pero que no conciernen más que a una pequeña minoría de la población activa? Otros estudios en otras ciudades nos mostrarán si Murcia es una zona en la que la hora de trabajo es más productiva que en otras partes.

¿Los trabajadores del sector de la construcción no son representativos, a pesar de los caracteres específicos de la construcción, de los asalariados urbanos? La organización del trabajo reviste rasgos análogos a los que se observan en otras ramas del artesanado. Gracias a ellos, ¿no será acaso la retribución de las dos grandes categorías de trabajadores urbanos que podemos conocer? 
$33,5 \%$

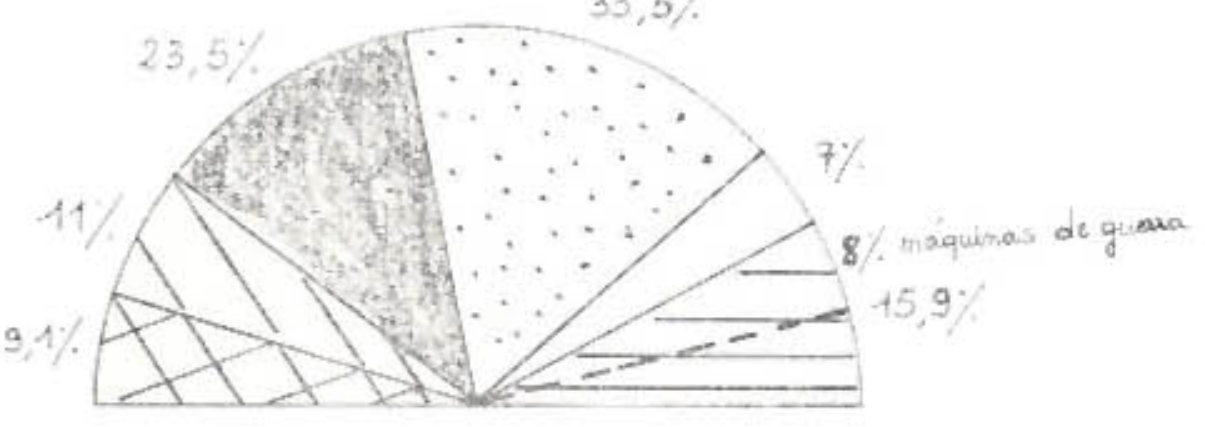

1391.1392

\section{EILIIARFS Y DR-LWSIVOS (incluso gastos}

de construcoíon de engtמos de sitifo)

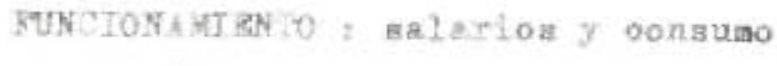

eoreajil.

C CORBBOS, MENSA WHOS Y PROCURADORES (+ pleitos en 14.26-23)

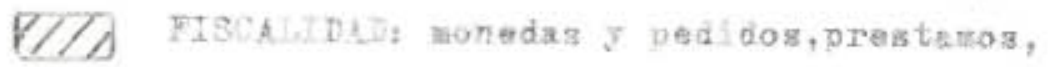
regelos forrsào, gestoz de parcepotion

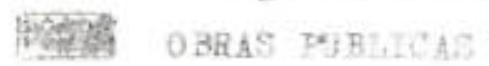

DI BRENEOINOS DE PRESTAMS

XY VAROS
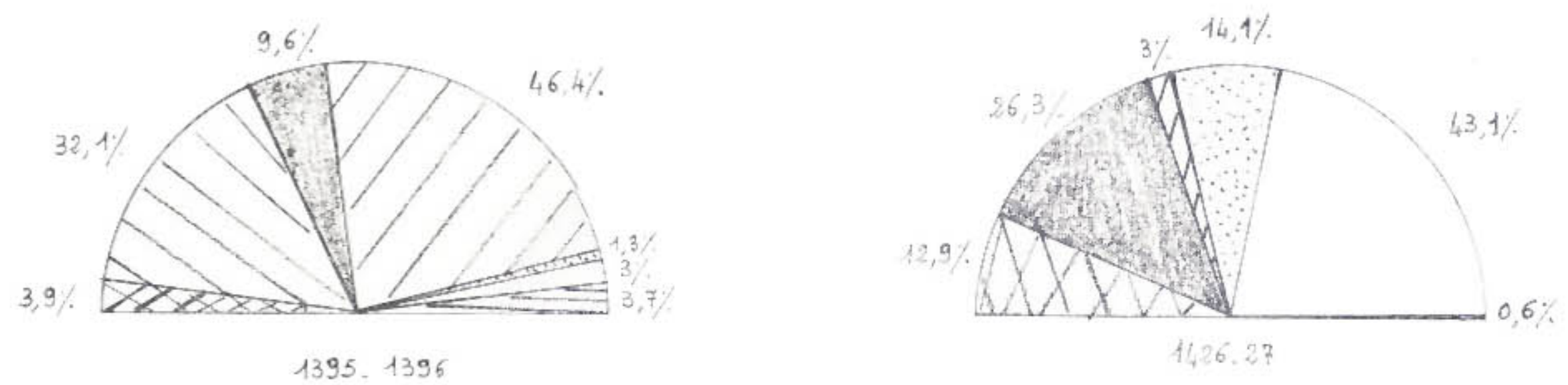

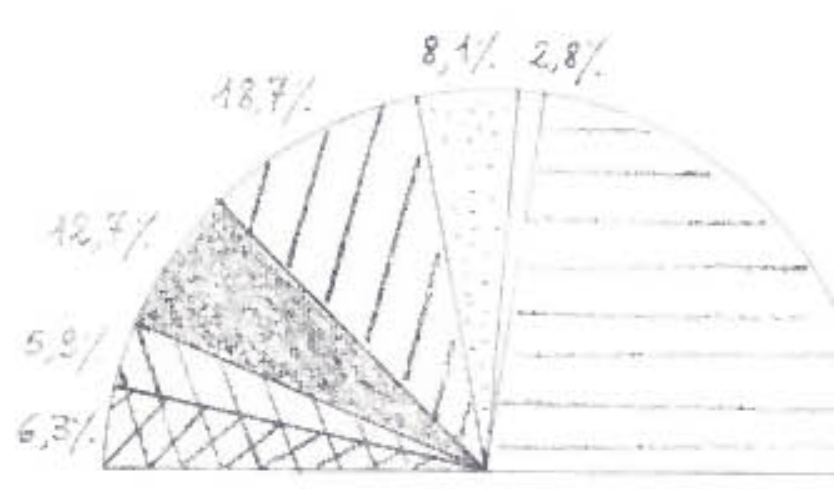

1429.1430 
ANEJO II

GASTOS EN OBRAS (en maravedís)

\begin{tabular}{|c|c|c|c|c|c|}
\hline & 1391.92 & $1395-96$ & $1407-1408$ & $1426-1427$ & $1429-1430$ \\
\hline $\begin{array}{l}\text { Obras públicas ...... } \\
\text { Máquinas de guerra . }\end{array}$ & $\begin{array}{r}15.847 \mathrm{~m} .+5 \mathrm{~d} \\
5.425 \mathrm{~m} .+1 \mathrm{~d} .\end{array}$ & $17.672 \mathrm{~m} .+5 \mathrm{~d}$ & $\begin{array}{l}7.213 \mathrm{~m} . \\
6.762 \mathrm{~m} .+5 \mathrm{~d}\end{array}$ & $23.429 \mathrm{~m} .+5 \mathrm{~d}$ & $19.463 \mathrm{~m} .+5 \mathrm{~d}$ \\
\hline de los gastos $\ldots \ldots$ & $\begin{array}{c}21.272 \mathrm{~m} .+6 \mathrm{~d} . \\
31,5 \%\end{array}$ & $\begin{array}{c}17.672 \mathrm{~m} .+5 \mathrm{~d} . \\
9,6 \%\end{array}$ & $\begin{array}{c}13.975 \mathrm{~m} .+5 \mathrm{~d} . \\
2,3 \%\end{array}$ & $\begin{array}{c}23.429 \mathrm{~m} .+5 \mathrm{~d} . \\
26,3 \%\end{array}$ & $\begin{array}{c}19.463 \mathrm{~m} .+5 \mathrm{~d} . \\
12,7 \%\end{array}$ \\
\hline
\end{tabular}




\section{ANEJO III}

\section{ALGUNOS PRECIOS}

I. Precios del. cahlz de trigo

\begin{tabular}{|c|c|c|c|c|}
\hline Fechas & \multicolumn{3}{|c|}{ Precios } & \multirow{2}{*}{$\frac{\text { Fuentes }}{\text { A. C. - L. } 0 .}$} \\
\hline 23. $7-1384$ & \multicolumn{3}{|c|}{80 maravedis de 3 blancas } & \\
\hline $48-1393$ & 40 & b & $\triangleright$ & A. C. - L. O. \\
\hline $17-12-1395$ & 50 & D & $D$ & A. C. C. M. \\
\hline $248-1396$ & 50 & $\triangleright$ & D & A. C. - L. O. \\
\hline 22-12-1399 & 40 & 2 & 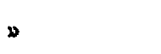 & A. C. - L. O. \\
\hline $24-7.1403$ & 65 & $\nu$ & $\triangleright$ & A. C. - L. O. \\
\hline $28-3-1407$ & 80 & $\triangleright$ & 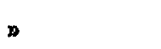 & A. C. - L. O. \\
\hline 5. 1.1408 & 110 & 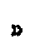 & $\infty$ & A. C. C. M. \\
\hline 9. 41413 & 135 & 》 & $\triangleright$ & A. C. - L. O. \\
\hline $1-7-1414$ & 120 & $\triangleright$ & $\gg$ & A. C. - L. O. \\
\hline $12-11-1429$ & 90 & 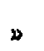 & 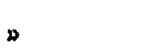 & A. C. C.M. \\
\hline
\end{tabular}

II. Precios del. CAHfz de Cebada

\begin{tabular}{|c|c|c|c|c|}
\hline Fechas & & Precios & & Fuentes \\
\hline 23. $7-1384$ & 50 & maravedis de & 3 blancas & A. C. - L. 0 . \\
\hline $4 / 9-12-1391$ & 22 & » & D & A. C. C. M. \\
\hline 27- 7-1395 & 18 & $\triangleright$ & $D$ & A. C. C. M. \\
\hline $16-1 / 25-2-1396$ & 20 & 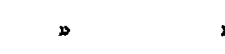 & D & A. C. C. M. \\
\hline $10-11-1426$ & 36 & $D$ & 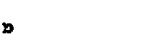 & A. C. C. M. \\
\hline 23- 2-1427 & 39 & D & 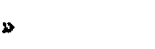 & A. C. C. M. \\
\hline 27. $7-1429$ & 60 & 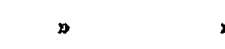 & $\infty$ & A. C. C. $M$. \\
\hline 17. $9-1429$ & 63 & $\triangleright$ & D & A.C.C.M. \\
\hline 20-9.1429 & 62 & , & D & A. C. C.M. \\
\hline $3-11-1429$ & 78 & $\bowtie$ & » & A. C. C. M. \\
\hline 20. $4-1430$ & 72 & $\infty$ & ๖ & A. C. C.M. \\
\hline
\end{tabular}


III. Precios fijados de la libra de carne: carnero, cabrón, oveja, vaca Y cabra

\begin{tabular}{|c|c|c|c|c|c|c|c|}
\hline & \multicolumn{2}{|c|}{ Carnero } & \multicolumn{2}{|c|}{ Cabrón } & \multicolumn{2}{|c|}{ Oveja, vaca, cabra } \\
\hline & & $A$ & B & A & B & A & $\mathbf{B}$ \\
\hline 138485 & $\ldots$ & $3 \mathrm{~m}$ & $3 \mathrm{~m}_{*}+2 \mathrm{~d}$ & $2 \mathrm{~m} .+4 \mathrm{~d}$ & $2 \mathrm{~m} .+6 \mathrm{~d}$ & $18 \mathrm{~d}$. & $20 \mathrm{~d}$ \\
\hline $1394-95$ & $\ldots$ & $3 \mathrm{~m}$ & $3 \mathrm{~m} .+2 \mathrm{~d}$ & $2 \mathrm{~m} .+2 \mathrm{~d}$ & $2 \mathrm{~m} .+4 \mathrm{~d}$ & $18 \mathrm{~d}$. & $20 \mathrm{~d}$. \\
\hline 1405.06 & $\ldots$ & $14 \mathrm{bl}$. & $14 \mathrm{bl}$. & $12 \mathrm{bl}$. & $12 \mathrm{bl}$. & $10 \mathrm{bl}$. & $10 \mathrm{bl}$. \\
\hline 1407.08 & $\ldots$ & $16 \mathrm{bl}$. & $16 \mathrm{bl}$. & $14 \mathrm{bl}$. & $14 \mathrm{bl}$. & $12 \mathrm{bl}$. & $12 \mathrm{bl}$. \\
\hline $1412-13$ & $\ldots$ & $14 \mathrm{bl}$. & $16 \mathrm{bl}$. & $12 \mathrm{bl}$. & $12 \mathrm{bl}$. & $10 \mathrm{bl}$. & $10 \mathrm{bl}$. \\
\hline $1413-14$ & $\ldots$ & $15 \mathrm{bl}$. & $16 \mathrm{bl}$. & $13 \mathrm{bl}$. & $14 \mathrm{bl}$. & $11 \mathrm{bl}$. & $12 \mathrm{bl}$. \\
\hline
\end{tabular}

A-de Carnestolendas a San Miguel.

B-de San Miguel a Carnestolendas. 


\section{APENDICE DOCUMENTAL I}

Ordenanzas de los Carpinteros (20 octubre 1394) A.M.M. A. C.-L. O. 1394-1395.

Este dia en el dicho conceio fue fecha relacion por Tomas de Monzon e Pedro Franqui que son de los 40 omnes buenos regidores del Conceio de la dicha çibdat deste anno presente e dixeron de como por el dicho Conceio les fue encomendado agora pocos dias han pasados para que viesen e corrigiesen e hemendasen las ordenaciones fechas e presentadas ante el dicho conceio por parte de los maestros carpenteros vesinos de la dicha çibdat en rason del oficio de la carpenteria e que ayan visto e corregido e hemendado las dichas ordenaciones las quales eran agora muy bien fechas e a pro comun de los vesinos e moradores de la dicha çibdat las quales dichas ordenaciones por los dichos Tomas de Monzon e Pedro Franqui fueron presentadas en un quaderno de papel, seyendo y presentes Martin de Calatayud y Alfonso Meanes carpenteros jurados del dicho oficio deste anno presente, las quales ordenaciones fechas e ordenadas por los dichos maestros carpenteros e corregidas e hemendadas por los dichos dos omnes buenos regidores sobre dichos son estas que se siguen:

21 de septiembre de 1394: este dia se allegaron todos los maestros de la fusteria: Juan Dominguez, Juan de Calatayud, Ponce Martinez, Jaime Mulet, Alfonso Ibañez, Martin de Calatayud, Miguel de Calatayud, Juan Perez, Juan Ibañez, Alfonso Mean, Yuste Perez, Alfonso Ferrandez los quales se ayuntaron e fueron movidos por mandado de los jurados de la noble çibdat de Murcia con el peon de Conceio e Ordenaron e tuvieron por bien estas ordenaciones:

1. Primeramente, ordenaron e tuvieron por bien que ningunt car- 
pentero non sea osado de labrar ni de usar de la carpenteria sy non fiere examinado con los jurados del oficio e acompanados so pena de 60 maravedis.

2. Ordenaron ... que puedan yr los jurados a requerir los obradores en el mes una vez.

3. Otrosi ordenaron ... que ningunt non sea osado de cortar madera en la menguante sy non la que pierde foja e que la corten en los meses de septiembre, octubre, noviembre e diciembre e non en otro tiempo, salvo la que fuere menester para los molinos que se corte en qual tiempo fuere menester, e la que non pierde foja en la creciente e sy la fallaren que non fuere cortada de luna e cada una como pertenesce que ge la troçearan a su costa e la traeran al mercado a su costa e la quemaran e pagara 60 maravedis salvo en pos que los maestros de fazer arados que corten la madera que ouieren menester cada que lo ayan menester de cortar es a saber la que perdiere foja en la menguante e la que non pierde foja en la creciente e sy de otra guisa la fisieren que pagen la pena que mandan las ordenaciones suso dichas que fallan en este caso.

4. Otrosi ordenaron ... que qualquier maestro que asegurare obra qualquier que sea e sy acaesciere que alguna mengua viniere que el que la asegurare que se para el menoscabo que viniere.

5. Otrosi ordenaron ... que qualquier que sea escogido para ser jurado del oficio e non lo quisiere ser que peche en pena 60 maravedis e esta pena que ge la puedan levar los jurados viejos del dicho oficio esta sobre dicha pena que fagan los jurados con los otros maestros lo que tovieren por bien e sy esto sobre dicho non cumplieren los jurados viejos del oficio que lo pagen ellos con el doblo.

6. Otrosi ... que qualquier que rebeldare o dixere injuria al jurado 
veyendo obra alguna o estando en juisio que sea prendado por $60 \mathrm{ma}$ ravedis e esta sobre dicha pena que sea para los jurados del oficio.

7. Otrosi... que a qualquier alguazil que le fuere mandado que prende prenda o prendas por mandado de los jurados del sobre dicho oficio que lo faga e que le pagen su derecho.

8. Otrosi... que qualquier maestro que toviere obra alguna començada e otro lo entere en la obra syn su licencia que pechen 60 maravedis e sy el maestro que la tal obra començare e prolongare de lo fazer quel senor de la obra lo pueda fazer acabar a otro qualquier e aquel a quien la fiziere acabar que lo pueda fazer syn pena alguna. La pena de los 60 maravedis que sea para los jurados del oficio.

9. Otrosi... que qualquier que debiere o ouiere a dar dineros o maravedis algunos a qualquier maestro fustero por obra que aya fecha que asy como dicho que los jurados del oficio puedan apremiar al qualquier maestro que acabe la obra que empieza que asy pueda apremiar al senor cuya fuese la obra que le paga su trabajo e salario e que pueda poner en ello pena de 12 maravedis de toda obra que fuere de valor de 12 maravedis arriba e sy fuere de menor quantia que le pongan pena guisada.

11. Otrosi... que los jurados del oficio luego que la fiesta de $\mathrm{S}$. Johan fuere pasada dentro dies dias ayan fecho allegar cabildo e se ayunten todos los del oficio en pena de cada 12 maravedis e que escogan de entre sy cadano dos omnes buenos por jurados del su oficio fasta la otra fiesta de S. Johan e que les presentan ante los jurados de la çibdat por que les tomen la jura. Estas penas que sean de los jurados del oficio.

E leydas e publicadas fueron las dichas ordenaciones en el dicho conceio ante los dichos omnes buenos e oficiales e publicadas aquellas el dicho conceio e omnes buenos e oficiales ouieren las por buenas a 
bien fechas e a pro común de la dicha çibdat e de los vecinos e moradores della otorgaron e confirmaron las e dieron las por firmes e por valederos ordenaron e mandaron que daqui adelante sean complidas $e$ tenidas e observadas e guardadas... 


\section{APENDICE DOCUMENTAL II}

Ordenanzas de los albañiles (17 diciembre 1401) (+) A.M.M. A. C.-L. O. 1401-1402, fol. 165 r.-166 r.

- Otrosi mesmo qualquier maestro que començare obra en casa de algund vesino de la dicha çibdat que sea tenido de lo acabar e que non vaya a parte ninguna fasta que aquella sea acabada syn voluntad de su sennor en pena de 12 maravedis.

- Otrosi quel sennor de la obra sea tenido de dar buena manobra al maestro e sy non ge la diere e quisiere dar que faga con que se vaya e quel almotacen sea tenido de les pagar los jornales al sennor de la obra.

- Otrosi si algund maestro labrare en casa de algunt vesino non lo quisiere pagar que ningunt maestro non sea osado de yr a labrar a la tal obra fasta quel maestro sea pagado en pena de 12 maravedis.

- Otrosi quel almotacen e los jurados del oficio sean tenidos de yr dos veces en el anno por la çibdat visitar paredes, aleras, cerramientos de camaras que afruentan con las calles que fagan derribar o adobar a sus duennos e quando vayan que vayan con el notario a este que sea pagado de los que no compliran mandado del almotacen e sy asy non lo fisieren e algunt dano ha acaesciere que se paren ellos e sus bienes.

- Otrosi que todos los maestros que labraren en la cibdat fagan las obras a conoscuda de los jurados del oficio e el que lo non supiere faser que venga a demandar conseyo a los jurados del oficio en pena de 12 maravedis.

- Otrosi que ningund que venga antel almotacen con pleyto alguno 
que non lo aya por escripto por quanto las cosas son peligrosas e non se podrian detener e sy es cosa que el pleyto aya de venir a sentencia que la juran que la parte el almotacen e los jurados.

- Otrosi que todas las penas que cayeren los maestros albanies sean para el almotacen e los jurados e que non sean tenidos de yr mas de una ves a ver los contratos e sy en aquella ves non se pudieren a venir que por cada ves que vaya que les den sendos maravedis.

- Otrosi que qualquier maestro que pajare pared o cubierta e enbargare la calle que dentro en treinta dias aya fecho la lavor desenbargare la dicha calle et el que non lo fisiere dentro en los dichos treinta dias que caya en pena de 12 maravedis la meatad para el almotacen e la otra meatad para los jurados del dicho oficio.

- Otrosi que sean tenidos de faser de cada anno los jurados viejos a los nuevos por la fiesta de S. Johan de junio asy de cada anno dentro en tercero dia en pena de 12 maravedis e que sean omnes buenos sabidores del dicho oficio. 